packs of cards. She could not give instructions on her own initiative.

Sir Francis Jeune said the mode of arriving at the wishes of the testatrix was novel, well intentioned, and most ingenious, and on the whole satisfactory. Taking the matter as it stood, nothing could have been more fair or more skilful, and he pronounced for the will, the costs to come out of the estate.

\title{
Editorial Comment.
}

The development of the JOURNAL is a matter of interest to all our members. It is published by the authority of the Association, and should therefore form, as we hope it does form, a fair index to the vital force of that body. The production of such a periodical, maintaining the high standard at which the Journal of Mental Science has always aimed, is nowadays not an easy task. There is immense activity in the field of psychiatry, and great efforts are being made everywhere to enable our science to keep pace with the general progress of medicine and with the rapid advance of some other and younger specialities.

Every year sees the establishment on the Continent and in America of new periodicals dealing with medico-psychology in its scientific aspects and as an art. Reference to our quarterly exchange list of journals will show a few of those which seem most representative and most valuable; but in addition to special journals we receive numerous reprints of articles from general medical journals dealing with our subject, as well as monographs, detached papers from works by several authors, etc. Surveying the vast and rapidly increasing volume of work which is being accomplished on all sides, there devolves upon us the arduous endeavour to keep pace with the entire progress of psychiatry, and to present to our busy readers wellsifted and thoroughly modern summaries of results.

It has for some time been evident that re-organisation is necessary in that department which deals with the current literature of insanity. The rearrangement of the Psychological Retrospects which have been prepared year by year at the cost of no little time and energy has been undertaken by 
Dr. Lord, with the active co-operation of those who have already done much for the JOURNAL, and of those who willingly promise their services in the future. The preparation of these retrospects represents much reading and sustained effort on the part of skilled and competent specialists, and we doubt if the labours of these workers have been adequately recognised by the Association.

We cannot revert to former volumes without rendering a tribute of hearty thanks to the earlier workers in this field, among whom may be mentioned veterans like Dr. Ireland and Dr. T. W. McDowall.

It will be observed that the abstracts are now classified and generally signed by those responsible for them, and it would appear that the time has come when reviews of more important works should also, as a rule, be signed by individual reviewers.

It is also designed that critical digests of important subjects shall be published from time to time, thus resuming a method which this JOURNAL was among the earliest to adopt, and which, as developed by other periodicals, has seemed to us most serviceable.

The progress of knowledge makes readers more critical, the advance of science calls for greater exactitude; but, apart from the literary and scientific aspects of our task, its business side does not grow easier. The production of plates and diagrams, for instance, almost indispensable nowadays, is costly and troublesome to every one concerned. It is pleasant, on the other hand, to note that the sale of the JOURNAL is increasing, until 1000 copies are hardly sufficient to meet the demand, notwithstanding that the price was materially raised some years ago. Advertisers are beginning to recognise the advantages which so widely read a journal offers them, and thus some relief of the expenses of publication is obtained by the Association.

We cannot forget that the Journal of Mental Science continues to stand as the sole representative of Psychiatry in this country. Nearly half a century has elapsed since the Association began to publish a journal. It has a long and honourable record. We doubt if the founders of the JOURNAL were sanguine enough to anticipate the success which has followed upon their venture, but we are assured that they would not 
have been content to stop short while progress is possible. We are mindful of the words in which Dr. Savage repudiates self-satisfied science, and of Landor's saying that those who are not quite satisfied are the sole benefactors of the world.

We confidently appeal to the members, and especially to the younger members of the Association, to increase their efforts to keep the JOURNAL in the front rank by the only method whereby that end can be attained, the contribution to its pages of work of real importance. Only by a constant show of continually improving work can any medical journal maintain a foremost place in modern times.

\section{Part II.-Reviews.}

\section{A System of Medicine by Many Writers. Edited by Thomas Clifford} Allbutr. London : Macmillan and Co., r899. Vol. viii, pp. 998. Price 25 s.

ThE final volume of Professor Clifford Allbutt's System of Medicine, containing as it does the section on "Mental Diseases," is the one which will prove of most interest to the readers of our Journal. The list of the contributors is a sufficient guarantee that the quality of the section is maintained at the same high standard which characterises the work in its entirety. That nervous and mental diseases, taken together, would seem to receive very full treatment is evidenced by the fact that the sections devoted to these occupy nearly 1800 out of the total of about $7800 \mathrm{pp}$., and yet we could have wished that more space had been devoted to the latter, which are disposed of in only $3^{\mathrm{I}} 5 \mathrm{pp}$., or 4 per cent. of the whole. From the point of view of the general practitioner, who is chiefly concerned with the treatment and difficulties arising in cases of threatened outbreak of, or fully developed, mental disorder among that class of society from which private patients are drawn, the treatment is sufficiently full and adequate. In the case of the poorer classes of the community, where no less than 90 per cent. of the existing lunacy has its origin, the difficulties that present themselves to the attending physician in a case of mental disorder are easily resolved. In the ordinary run of cases it means relegation to the asylum. In the case of the well-to-do the difficulties are enormously increased, and, after perusal of the section, the general impression that one gets is that the various contributors, in their recommendations as to care and treatment, had this class specially in view.

In recent years the additions to our knowledge of disease have been many and great, and these have always had as their consequence the 